\title{
Barriers of Knowledge Transfer between Globally Distributed Teams in ICT Product Development
}

\author{
Aicha Togola \\ Swedish Center for Digital \\ Innovation, Department of \\ Informatics, Umeå University \\ aicha.togola@umu.se
}

\author{
Safa Ahmed \\ Swedish Center for Digital \\ Innovation, Department of \\ Informatics, Umeå University \\ safa.ahmed@umu.se
}

\author{
Taline Jadaan \\ Swedish Center for Digital \\ Innovation, Department of \\ Informatics, Umeå University \\ taline.jadaan@umu.se
}

\begin{abstract}
Increased globalization has generated a growth of globally distributed teams, which are characterized by geographical distance and used by organizations to increase innovation. However, to be able to collaborate effectively, teams are obligated to continuously conduct knowledge transfer (KT) between different geographical locations. Thus, this paper focused on identifying the main barriers that globally distributed teams face in conducting KT and how these barriers are unraveled. Based on an interpretative case study of a product development unit (PDU) in research and development $(R \& D)$ department of a telecom company, we identified eight main barriers that hinder the KT between globally distributed teams. These barriers are; knowledge embeddedness, knowledge accessibility and documentation gaps, knowledge complexity, knowledge problematic articulability, ICT tools reliance vs. face to face, inefficient ICT tools utilization, inefficient IT support, and lack of formal processes and guidelines.
\end{abstract}

\section{Introduction}

Knowledge is recognized as one of the most critical resources in an organization which is unique, valuable, and inimitable [4]. Effective knowledge transfer (KT) can improve the organization's performance, adaptation, collaboration, decision making, resource management and innovation [20]. In order to improve the effectiveness of KT processes and outcomes, it is crucial to understand the barriers associated with it [36]. Here KT is defined as knowledge being transferred from one entity (e.g., an individual, group, or organization) to other entities [21]; it can happen between two units of the same firm, or through a market transaction between two separate firms. Some researchers argue that the challenge of KT grows in complexity if the source and the recipient are located in different geographical locations [29], [11].

Multiple studies have focused on KT within different organizational Settings. However, few empirical studies focused on the barriers of KT in ICT product development projects area, where the sort and the content of knowledge are different, as these projects include software, hardware and building practices that make the KT even more complex [7]. Cumming and Teng [7] conducted a study on the key factors affecting KT success in R\&Ds. However, they did not look into the specific elements of these factors that could be barriers to KT and how they could affect it. Further, the authors suggest that looking at KT research from the technology transfer/innovation and strategic management fields, four broad contexts areas affect the KT; knowledge context, relational context, recipient context, and activity context. Moreover, most of the studies on the factors affecting KT are of a quantitative nature focusing on project management. This paper focuses on the knowledge and activity context in Cumming and Teng [7] framework using an interpretative case study approach and aiming to reduce the gap in the research area regarding the barriers of KT between globally distributed teams.

This study considers respondents from different areas, e.g., project management, design, production. Therefore, our research question is: "What are the key barriers of knowledge transfer that globally distributed teams in ICT product development projects face and how do these barriers affect knowledge transfer?". To address this question, we used the knowledge and activity context in Cumming and Teng framework [7] to conduct an interpretative case study in a product development unit (PDU), at a telecom company, where the main projects types are new product development (NPD). 


\section{Knowledge, Knowledge management, and Knowledge transfer}

Many IS researchers acknowledged that knowledge is a fundamental asset for firms in today's contemporary economy [1], [33]. Knowledge is here defined as information combined with experience, context, interpretation, reflection, intuition, and creativity [8], [23]. Knowledge differs across firms [38], and it is asymmetrical and unequally distributed within firms [8]. According to Vance and Eynon [38], this uneven distribution of knowledge within organizations is the reason why organizations develop knowledge management strategies in an attempt to move knowledge from where it is to where it can be applied to leverage objectives. An essential aspect of knowledge management is the process of KT between different parts of the organization [4], [1].

KT in organizations is "the process through which one unit (e.g., individual, group, department, division) is affected by the experience of another" [2, p. 151]. The transfer of knowledge resources from source units to destination units where they are needed is essential to extend the range of applicability of the firm's knowledge resources [33]. However, knowledge is recognized to be sticky and contextualized as a result of which it might not be readily transferable [36], and if the required knowledge cannot be transferred to the correct person, the processes flow incorrectly, and disruptions emerge as a result [22].

\subsection{Distributed teams and $K T$ in a global setting}

Globally distributed and virtual teams have become more and more popular with the advent of globalization, and they have also received significant attention over the past decade from IS and management researchers [12]. Such teams are characterized by geographical and time zone distance and a heavy reliance on ICT tools for collaboration [13]. Organizations increasingly employ globally distributed teams to foster innovation [13], [12]. Thus, organizations need to exploit the diverse knowledge and expertise available within the distributed teams [25]. Compared to traditional organizational settings, globally distributed teams face significant challenges in the coordination and transfer of knowledge across different sites due to the geographically dispersed nature of knowledge and the lack of common knowledge between team members [29], [30]. Many cases exist where KT activities did not achieve their objectives due to the vast diversity of potential barriers [30]. Cumming and Teng [7] framework (see fig.1) presents the KT from four broad contexts that can be studied as areas that affect the KT: knowledge context, relational context, activity context a recipient context. However, as mentioned earlier, this study focused on the knowledge context and activity context.

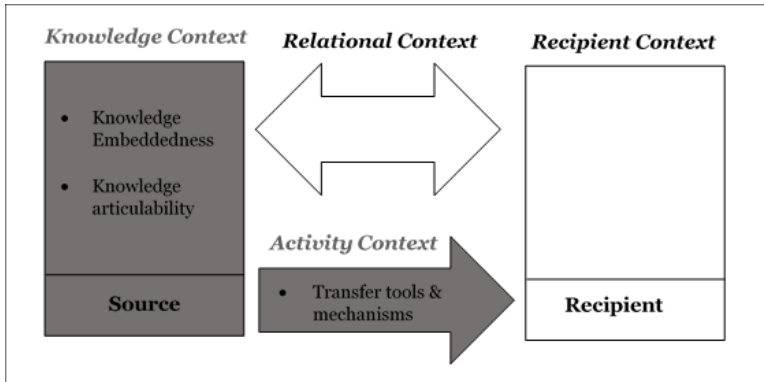

Figure 1. The study is focusing on two contexts of Cumming and Teng's Framework

2.1.1. Knowledge context. Researches looked into the knowledge for effective global teams, and product development for global markets; like Subramaniam and Venkatraman [35] who discussed the impact of tacit overseas knowledge; or Kogut and Zander [24] who researched in the area of location-specific knowledge. Furthermore, in his article, Goh [15] argued that the type of knowledge to be transferred affects the needs and conditions for the KT process. These arguments make the knowledge context a vital aspect of studying when attempting to understand the $\mathrm{KT}$; especially in product development which is a complex activity that is dependent on both knowledge and learning [14]. The process of product development generates a considerable amount of knowledge. Cohen and Levinthal [5] used the term "the dual role of innovation" for the product development, where there is the generation of not only the technical knowledge but also knowledge on organizational processes. In their framework, Cumming and Teng [7] presented two factors in the knowledge context that is affecting the KT: Knowledge embeddedness and knowledge articulability.

Knowledge embeddedness is an essential characteristic of knowledge [7]. When considering the knowledge embeddedness, one needs to think of which elements and related sub-networks needed in order for the knowledge to be transferred, absorbed, adapted and adopted by the recipient [7]. Knowledge can be embedded in individuals, and whether tacit or explicit, such knowledge can be transferred by transferring individuals [34]. When no personnel transfers are accompanying KTs, recipients often fail to learn all the different routines [27]. Argote and Ingram [2] also present a framework which supports that knowledge in organizations can be embedded in three different 
elements: members, tools and tasks, or the combinations of these. Also, global product development demands dealing with differences in the markets, and much of the location-specific knowledge is claimed to have a connection to local market requirements. This location-specific knowledge is to a large extent tacit by nature, and therefore difficult to transfer between globally dispersed teams [35]. KT can also be affected by knowledge articulability, or the extent to which knowledge can be verbalized, written, drawn, or articulated [4]. Articulable knowledge is more easily transferable than less-articulable knowledge [7], [41]. [19, p. 13] also support that "poorly articulated knowledge is difficult to teach and learn." The problem of knowledge articulability can be related to the knowledge type. Knowledge could be explicit or tacit. Tacit knowledge is knowledge that is difficult to communicate and formalize because it is contained within the individual and usually gained through experience or personal skills [28]. It has been acknowledged that much of the knowledge generated in product development is tacit; which is difficult to express, connected with problem-solving, and dependent on the interactions within the team [14]. [7] support this by arguing that individuals know more than they can explain because individuals possess tacit knowledge that is non-verbalized, intuitive, and unarticulated. In their framework (see fig.1), Cumming and Teng [7] also presented their basic argument that KT success requires that both parties develop an understanding of where the desired knowledge resides, Kanat, and Atilgan [22] also agreed with this argument as they concluded that most of the KT problems originate from non-accessible knowledge. Cumming and Teng [7] refers to Dixon [10] by arguing that it is crucial that both (sender and receiver) participate in the processes by which the knowledge is made accessible. They argued that the involvement in the articulation process supports the recipient's later ownership and commitment to the knowledge and also that it enhances the relationship between the source and the recipient.

2.1.2. Activity Context. In this study, the activity context is mainly concerned with $\mathrm{KT}$ mechanisms and tools that are used to transfer knowledge between team members. This study will investigate more the role of ICT and the barriers in this area as Cumming and Teng [7] didn't elaborate on the transfer mechanisms and tools in the activity context and specifically not on the role of ICT in KT activities.

ICT and knowledge transfer ICTs are usually recognized as the solution to organizational KT for geographically dispersed teams [37]. ICTs have helped in bridging temporal and spatial barriers by facilitating distributed and virtual communication and coordination of work [17], [37]. Hendriks [19] identifies four potential roles of ICT in KT: First, ICT can be helpful in reducing some barriers involved in KT such as temporal, physical, and social distance. Second, ICT can also facilitate the access to information bases that are storing data by the use of tools such as document information systems. Third, ICT may be used to enhance KT processes by supporting or directing KT processes. Finally, ICT can be used to find the different elements relevant to the process of KT such as knowledge owners and knowledge re-constructors.

On the other hand, Robey et al. [32] classified ICTs used by virtual teams into two groups: technology that allows for synchronous (same time, different place) interaction and for asynchronous (different time, different place) interaction. Synchronous ICTs include telephone/audio conferencing, live application sharing, video conferencing, instant messaging, and electronic whiteboarding; Asynchronous ICTs include email, shared document repositories, and threaded discussions [26]. Moreover, Griffith et al. [16] argued that groupware tools such as Lotus Notes support longdistance collaboration and knowledge exchange. However, even though without IT systems, most KT practices would be less effective and applications less timely [30]. It is essential to understand that IT systems ability to enhance KT practices is not universally applauded [6]. Some researchers argue that ICT as a mean to enhance KT may also introduce ICT specific barriers in KT and addressing these technology barriers is vital for organization KT improvement [30].

\subsection{ICT related barriers}

In their study, Han and Anantatmula [18] found that organizations usually invest in IT/IS tools in the hope to willingly engage employees in KT. However, according to them, this has resulted in some disappointments since IT could not achieve what they wanted [18]. Some scholars found that virtual teams may have a disadvantage because face-to-face meetings are essential for some sorts KT activities [7], [21]. Face-to-face communication plays an essential role in the process of KT between intra-firm units such as new product development teams [21]. It can be difficult for ICT to replace the rich interactivity, and communication that is present in conversation; because sometimes it is easier to get some knowledge through a conversation with the actual expert than from an IT system [6]. Dedrick et al. [9] also support that tacit knowledge is usually transferred through face-to-face meetings or other interactive means. Riege [30] introduced the following factors that could be potential barriers of KT at a technology level; Lack of 
integration and compatibility of different IT systems and processes, mismatch with employees' need requirements, reluctance to use IT systems and unrealistic expectations. Thus, this unfamiliarity and lack of experience with IS/IT systems could be a potential barrier to KT [6]. This problem could arise due to the lack of training and communication regarding new systems and processes [18]. If employees do not possess the required skill to use a technology, it is unlikely that they will effectively interact with each other even if the said technology has the right functionalities [18]. Also, the lack of technical support and a lack of instant maintenance and technical support of the systems can be annoying and eventually causes a barrier to work routines and KT [30]. Therefore, an immediate support function for technical faults is essential to provide timely solutions to system problems and anticipate future potential problems that could be an obstacle to effective KT [30].

\section{Method}

This study is based on an interpretative case study [39] [40] in a product development unit at a multinational telecom company. The interpretive nature of the qualitative research makes it adequate for this study in order to understand and analyze the barriers of KT between globally distributed teams in ICT product development projects.

\subsection{Research Context}

The study object of this paper is a product development unit (PDU) in the R\&D department of a multinational Telecom Company with sites in three main countries: Sweden, China, and Canada. Each development project has three sub-projects: hardware (HW), software (SW), and systems. As the names suggest, HW project focuses on the hardware, SW project focuses on the software part, and system project focuses on the standardization, systemization, customer requirements' definition, and functionalities definition as an input to the design teams. The meetings and communication between the different sites are mainly carried out through Skype for business, and other specific company developed ICT tools. Thus, a significant amount of knowledge is being transferred between the different sites. $\mathrm{KT}$ is essential to ensure the continuity and the quality of the products.

\subsection{Data Collection}

We collected our data through semi-structured interviews [40] and initiated the study by engaging with the employees at the R\&D unit in a more relaxed and informal way in order to understand how projects are conducted. This approach helped us construct our interview guide and enabled us to choose the respondents for future interviews. Subsequently, 12 interviews were conducted, and the average time of the interviews was 38 minutes. Participants were a mixture of project managers, design leaders, and chief engineers from Sweden, China, and Canada. Also, these participants worked in three different projects HW, SW, and systems Even though the primary data collection method for the study were the semistructured interviews we also used internal documents to learn more about the organizational structure before selecting the participants and constructing the interview questions. The interviews in Sweden were face to face interviews, while interviews with participants from China and Canada were carried out through Skype for business video calls. All these interviews were recorded and transcribed. For the sampling and the choice of participants, we tried to follow mainly purposive selection where we focused on the characteristics of the respondents to make a choice [31]. Our target was to interview people from the three different sites, organizational levels, and backgrounds to get more insight into the phenomena.

\subsection{Data Analysis}

Thematic analysis was used to analyze the collected data material from the interviews. We followed Braun and Clarke [3] six phases guide to conduct a thematic analysis. In the first phase, all the interviews were transcribed and read to get an in-depth understanding of the data collected and to prepare for the next stage of the analysis which is coding. In the second phase, the dataset was coded to generate the different categories. In phase three, the themes were determined by using a mix of data-driven and theory-driven approaches. We searched for themes based on our literature review but also based on the data itself to discover new facts that not implied in previous research. In the fourth phase, the relevance of the themes and the codes associated to them was verified. In the fifth phase, we made sure that all the themes are clearly defined and that their names are concise and easy to understand. The sixth phase focused on presenting a clear account of the findings.

\section{Results}

The results are structured based on the two contexts of Cumming and Teng's KT framework, knowledge context and activity context [7]. 


\subsection{Knowledge context}

For the knowledge context, we have identified four main barriers: Knowledge embeddedness, knowledge complexity, knowledge accessibility \& documentation gaps, and knowledge problematic articulability.

4.1.1. Knowledge embeddedness. This was one of the themes that were common among the respondents. Two types of knowledge embeddedness have been revealed: embeddedness in people and embeddedness in sites. All the respondents have agreed that embeddedness in people exists and that it is a barrier for PDUs. Our results show that there is a dependency on key people which are usually overloaded with work and don't have time to support the KT activities. A project manager from Canada quoted below pointed out that this dependency delays their activities and creates gaps in the design. "You don't have enough people that understand how that block works so when you try to design you have gaps in your knowledge, and then in the back end when you try to do integration and actually do the test you know you put the radio together and get it to work properly you have issues, and you don't understand whether it's in the design outside that subsystem or if there are issues within that subsystem; and that's problematic". Also, embeddedness in sites creates dependency for the teams in the other sites and can delay KT. A design leader from Canada quoted: "There is no Information or anything that we can do ourselves we were basically relying on them, so that is one aspect; all the platform leaders were all in Sweden as well."

\subsubsection{Knowledge accessibility and documentation}

Gaps. This barrier refers to the missing documentation, the inefficient process of updating and reviewing the documents, the questionable quality of the existing documents, the lack of clear database and file structures and the problems associated with access rights to the knowledge. The respondents explained how the missing parts are creating significant problems for them to understand the knowledge that is being transferred fully. A chief engineer from Canada quoted: "There were actually gaps in the systemization, and those gaps were really never resolved and were not documented, but they were still not impacting the previous project, but when we took the project and started making some changes we realized that those changes were causing us problems now because of the previous gaps and those were never documented, and we realize quite late in the project". The quality of the existing documentation is also questioned by the respondents, especially in the recipient sites. The chief engineer from Canada continued: "I would say we have a lot of documentation but some of it is redundant, and a lot of it can be based and delta of other documents, but there are scarce documents that explain the fundamentals of the design and how they interact and why the decisions were made". Furthermore, the process of reviewing and updating the documents is considered slow by some of the respondents, and in some cases, the updates of documents that are affecting both source and recipient products are not shared or spread in a good way create confusion and frustration for the recipient. Many respondents also mentioned that the knowledge accessibility problem could be caused by the lack of a clear database and file structure for the knowledge.

In some cases, people lacked access right to the knowledge storage locations. A design leader from Canada quoted: "I find that people will not necessarily summit to documentation, they just keep it in their laptops. That is again hard to find the certain information you want".

4.1.3. Knowledge complexity. This was a barrier that all respondents agreed upon. The analysis revealed that PDU knowledge is considered complex due to mainly two reasons: the use of new technologies and the content of the knowledge itself. For the first reason, PDUs in general work with new technologies all the time. These new technologies are sometimes considered not mature enough or even not wholly defined from standards perspective; that can hinder the $\mathrm{KT}$ process because there is still no mutual understanding or common ground between the source and the recipient for these new technologies, adding to that, the new terminologies that come with every new technology. All of these aspects make it hard for the source to understand and consequently transfer the knowledge fully. A design leader from Sweden quoted: "The main issue with the new technology would be if we don't understand then we cannot do this properly, then we can have some missing parts we don't understand the functions, or we don't understand the requirements." The second reason that explains why ICT product development knowledge is complex is linked to the content of the knowledge itself, our findings show that ICT product development knowledge is complex and that it includes different parts: HW, SW, and systems that are interacting in a very complex way which can be a challenge for the KT. A chief engineer from Canada quoted: "Most of the time you have a combination of SW and HW that is required as well, because we are delivering products and products are made of systems, HW components and SW components that all need to come together so that, when you have all that, all these different 
development technologies....we are using complex chips and designs and ASICs and things of that nature".

4.1.4. Knowledge problematic articulability. This barrier has two parts: the tacitness of the knowledge and the problems with the articulation process. From the results, it is evident that PDU knowledge is considered as a tacit knowledge that is difficult to communicate and transfer. One aspect that explains that tacitness is that some respondents believe that the majority of PDU knowledge was gained through experience and practice which is hard to articulate or document and as a result leads to more laborious transfer of this knowledge. A design leader from China quoted: "So many of this is related to experience; you work for the project, you work in this area for a long time, you have a lot of experience. These experience things are hard to transfer, this is actually extremely important in radio technology, the design experience. It's hard to be verbally crystal clear that everyone who will read it will know it immediately". On the other hand, for the articulation process, almost all respondents agreed that the articulation is done mainly by the source that is transferring the knowledge. Recipient in some cases came back with some questions but no major feedback on the content of the documentation. This can affect the sense of engagement that can boost the KT activities' quality. A chief engineer from Sweden quoted: "Usually I am doing the work here, but I want them to review all things, maybe they just correct errors not rephrase, maybe they can do it, Ottawa for the correction they maybe rephrase it to better English, but not in the knowledge itself, I usually write the document completely by myself, if I need assistance I take from the design team here".

\subsection{Activity Context}

For the activity context, we found four main barriers for KT namely: ICT tools reliance vs. face to face, inefficient ICT tools utilization, inefficient IT support, and lack of formal communication plans and guidelines for the KT.

4.2.1. ICT Tools Reliance vs. face to face. In KT, the lack of face to face interaction can become a barrier for KT. All the respondents emphasized that face to face $\mathrm{KT}$ is the best compared to using ICT tools, especially if the team members have never met before. A project manager from China quoted: "You know, I think for the most important things, face to face communication will make you understand more about what people want or know. For the language it can help you; and if we just use the conference call or we use email, yes, we can get specific things we want to know, we ask questions they give answer but if we have some face to face communication, face to face knowledge transfer, I think that we can get more compared with other tools".

4.2.2. Inefficient ICT tools utilization. Employees awareness of the functionalities and capabilities of ICT tools is essential for the effective utilization of ICT tools for KT. All the respondents emphasized that they are not aware of all the capabilities of the tools they use. A design leader from Canada and chief engineer from China quoted respectively: "There may be other features that we don't necessarily realize, that may improve things. So, some of them, the basic functions are fine no Problem but some of the others we don't know". "I think there were ways of doing new reviews with actually office 365 , which I am not actually sure about. So, we have started using PDF reviews, but there may be other ways of doing, sharing reviews differently as well". Our results reveal that the challenge of the employees' awareness of the capabilities of ICT tools may be related to the complexity of the tools and the lack of training on how to use the tools. Most respondents claimed that some tools are complicated to use. In addition, respondents claimed that they received no formal training on the ICT tools they use for KT which is also complicating things. Concerning these issues, one project manager from Sweden quoted: "I understand that there are so much more you could do with the tools, especially SharePoint but also like hansoft, you can create excellent reports and data and follow-ups, but they are quite complex to use." Also, our findings prove that the efficient utilization of ICT tools is also related to how well team members exploit the tools. Most respondents emphasized that video calls are rarely used. A project manager from Canada quoted below highlighted that using more video could help improve remote KT. "I think we should use more video, for some reasons we don't, there is a reluctance to do that at meetings, I think it enhances the relationship that you develop with people if you have video, not just the audio. Also, a lot of technical problems that one actually could benefit from is video. If you are working on a circuit board, for example, you can hold it up and show like you see this part here that is where the transistor is and so on..."

4.2.3 Inefficient IT Support. This can be a barrier to a successful KT in a product development project by affecting the effective collaboration between geographically separated team members. Most 
respondents claimed that IT support takes time to solve issues, which can impact KT activities across the different development sites. A project manager from Sweden quoted: "This SharePoint business that we were doing, this migration. Something that people are using to help over the night, or even you know, you shouldn't be able to notice it. If you have an Apple iPhone, you get update overnight, and you don't even know it, it just tells you, you have a new update. Here they shut down the project websites for two weeks and then when it comes back up it is so slow that you can't do work anymore". Respondents emphasized that the lack of competence of IT support is another challenge. This lack of competence caused an avoidance towards IT support where many people try to solve some of the issues themselves instead of requesting the support of IT. A design leader from Sweden quoted: "I usually avoid it, I go to my colleagues and ask. So, if Skype cannot start, I usually do something, I go in the task manager and kill these two processes like yeah, and it is easier like to call in, but in general people avoid calling if they are not forced to and for the non-urgent purposes you can send a mail or set up the service request." In addition to the above challenges, some respondents also mentioned that sometimes there is a misunderstanding when trying to explain the problem to the support because of the language barrier because IT support is usually outsourced.

4.2.4 Lack of formal communication plans and guidelines Formal communication plan is essential to ensure that team members have the contacts of all the people needed for the success of KT activities. All the respondents agreed that the lack of formal communication plans is creating some challenges for KT. A project manager from Canada and a project manager from Sweden quoted: "I would say it is a lot of experience based on starting up and having a contact network as well. So, you work with the board you know which one to contact, it's just individually based really. Also, I think many people are successful with their designs because they have their correct contacts, Unfortunately". Our findings prove that the communication plans must also include guidance and direction on which ICT tools to use for KT in order to make sure the most appropriate tools are used for a specific KT. All the respondents mentioned that no guidance on which tools to use for KT is also a challenge. A chief engineer from Canada quoted: "I think people are using more and more OneNote and SharePoint, creating their own private channel for sharing information within a project. There is no guideline, and there is no model".

\section{Discussion}

\subsection{Knowledge context}

5.1.1. Knowledge embeddedness. This remains as one of the most mentioned challenges and a primary barrier for the KT. In the specific case of ICT product development knowledge, our results revealed that embeddedness in people was the most common embeddedness theme. This is in line with what Moreland et al. [27] mentioned, that when no personnel transfers are accompanying KTs, recipients often failed to learn all the different tools and routines. Other researchers also highlighted that tacit knowledge is usually embedded in people [34]. Respondents also mentioned that some knowledge is embedded in sites and that this embeddedness in sites can also affect $\mathrm{KT}$. Previous literature supports this by acknowledging that knowledge can be embedded in sites and that this location-specific knowledge is to a large extent tacit, and therefore difficult to transfer between globally dispersed teams [35], and especially with the lack of face to face interaction that will be discussed in the activity context.

5.1.2 Knowledge accessibility and documentation gaps. This barrier is a new barrier that came up from the analysis and a one that previous literature did not reflect on. Cumming and Teng [7] only touched this area briefly by mentioning that $\mathrm{KT}$ success requires that both parties develop an understanding of where the desired knowledge resides. The barrier includes different challenges and issues such as the missing documentation, the lousy quality of the existing documents, the slow and inefficient process of reviewing and updating the documents, the unclarity associated with who maintain access to the knowledge databases, and also the unclear database and files structure. Also, instead of storing documents in the central databases, our study shows that some knowledge is kept in local computers or sites' local servers. Hence, recipient team members spend lots of time and efforts searching for some documents containing the knowledge they need. All this leads to highlighting the great importance of having well documented and easily accessible knowledge for having a smooth and efficient KT, especially with the complex nature of the knowledge for PDU that will be discussed next.

5.1.3. Knowledge complexity. This is a primary barrier that the previous literature including Cumming and Teng's [7] study didn't focus on. Knowledge complexity is a barrier that is linked to ICT product 
development knowledge specifically. Two aspects were linked to this barrier: the use of new technologies in ICT product development, and the type of the knowledge and the uniqueness of each product developed. As emphasized by the respondents, the new technologies lack maturity and precise definitions, terminologies, and standards. Hence, these made the KT more difficult. The second aspect was the type of knowledge and the uniqueness of each product. The fact that ICT product development requires $\mathrm{HW}, \mathrm{SW}$, and systems makes it more complicated than other types of product developments that include only HW or only SW. The complicated way refers to the parts that are interacting and creates challenges for transferring such knowledge. In addition, the unique characteristics for each product make product development knowledge harder to transfer. Goh [15] touched this area and mentioned that the type of knowledge to be transferred affects the needs and conditions for the KT process.

5.1.4. Knowledge problematic articulability. Cumming and Teng [7] already highlighted this barrier; that articulable knowledge is more easily transferable than less-articulable knowledge. Respondents mentioned that the difficulty with knowledge articulability is related to the tacitness of ICT product development knowledge. Goffin and Koners [14] acknowledged that much of the knowledge generated in new product development (NPD) is tacit; which is difficult to express, connected with problemsolving, and dependent on the interactions within the team that in this case is mainly through the ICT tools that have their limitations. Besides that, our study shows that the articulation is mainly carried out by the source. This lack of engagement from the recipient was brought up as a cause of frustration. It is essential that both the source and recipient participate in the processes by which the knowledge is made accessible [10] are engaged. Cumming and Teng [7] concluded that both sides involved in the articulation process supports the recipient's ownership and commitment to the knowledge and also enhances the relationship between the source and the recipient, which was also evident in our results.

\subsection{Activity Context}

5.2.1. ICT tools reliance vs. face to face. This study shows that the lack of face to face interaction is one of the main barriers for KT between globally distributed teams. Cumming and Teng [7] share this point of view by arguing that geographically separated teams may have a disadvantage because face-to-face meetings are essential for some types of KT activities. Participants emphasized that language barrier can be attenuated with face to face and that it can also help to build the personal relationship with team members. In the knowledge context, we argue that knowledge involved in ICT product development is complex and that it is based on experience and tacit knowledge. The use of ICT tools to transfer such knowledge is not very efficient. Participants stressed that compared to KT through ICT tools, face to face KT is better to get more understanding and more information. Connelly and Kelloway [6] support this point of view as they stated that it could be difficult for IT to replace the rich interactivity and communication that is present in conversation because it is easier to get knowledge through a conversation with the actual expert than from an IT system. Alavi and Leidner, [1] argue that knowhow and tacit knowledge is best transferred through interactive means such as travel for face-to-face meetings.

5.2.2. Inefficient ICT tools utilization. Our study revealed that team members awareness of the functionalities and capabilities of the tools is one of the most important things necessary for the efficient utilization of ICT tools for KT. Unfamiliarity and inexperience with ICT tools could be a potential barrier for KT [6]. In addition, the complexity of ICT tools may also cause a reluctance to use the tools. Riege [30] shares this opinion that people can be unwilling to use newly introduced systems because of the complexity of the system. Han and Anantatmula [18] support that the problem related to tools complexity and team members unfamiliarity with ICT tools could arise due to the lack of training regarding new systems and processes. Our study shows that the company does not usually organize training concerning the tools they use for $\mathrm{KT}$. However, one big challenge that previous research did not pay much attention concerning the utilization of ICT tools for remote KT is team members neglectance towards visual channels such as video calls. When KT is done through ICT tools, overlooking visual channels increases the challenges. Thus, the use of visual channels can improve KT.

5.2.3. Inefficient IT support. Efficient IT support is vital to ensure that team members receive all the necessary support to facilitate remote KT. Participants emphasized that the process for getting IT support is long and IT support takes a long time to solve issues which create challenges for KT. Riege [30] share this point of view as he argued that a lack of instant maintenance and technical support of the systems could be frustrating and eventually cause a barrier to work routines and $\mathrm{KT}$. Also, participants also 
complained about IT support competence and inability to solve some issues. One aspect that previous research did not focus on concerning this barrier is the language barrier between employees and IT support. Problems and misinterpretation of the problem can occur when users and IT support do not share the same native language.

5.2.4. Lack of formal processes and guidelines. In an ICT product development project involving team members in different countries, having formal processes and guidelines for KT activities is essential for the outcome of the KT. Goh [15], argues that the use of ICT tools for KT can only work if some other organizational factors are well managed. However, previous literature did not reflect much upon these organizational factors that could be a barrier to remote KT. The results of this study show that the lack of formal guidelines and communication plans is a significant barrier to KT. The communication plan needs to include many elements such as the list of contacts necessary for KT and a direction on which ICT tools to use for KT.

\section{Conclusion}

The objective of this research was to investigate the barriers of KT between globally distributed teams in ICT product development projects and how these barriers affect KT using Cumming and Teng's KT framework [7]. In the knowledge context, the main barriers that our study identified are knowledge embeddedness, knowledge complexity, knowledge problematic accessibility \& documentation gaps and finally knowledge problematic articulability. In the activity context, the main barriers that we identified are ICT tools reliance vs. face to face, Inefficient ICT tools utilization, inefficient IT support, and the lack of formal communication plans and guidelines. New barriers not mentioned in previous literature are knowledge complexity, knowledge accessibility \& documentation gaps, and the lack of formal communication plans and guidelines. As opposed to previous literature, this study also describes how the identified barriers affect KT between globally distributed teams; for example, how the neglectance of video calls can hinder remote $\mathrm{KT}$ or how the different aspects of knowledge complexity like the use of new technologies and new terminologies can complicate the KT. The study also helps practitioners with more understanding of the KT barriers that will help to tackle these barriers.

\section{References}

[1] Alavi, M., \& Leidner, D. E. (2001). Knowledge management and knowledge management systems: Conceptual foundations and research issues. MIS Quarterly, 107-136.

[2] Argote, L., \& Ingram, P. (2000). Knowledge transfer: A basis for competitive advantage in firms. Organizational behavior and human decision processes, 82(1), 150-169.

[3] Braun, V., \& Clarke, V. (2006). Using thematic analysis in psychology. Qualitative research in psychology, 3(2), 77101.

[4] Bresman, H., Birkinshaw, J., \& Nobel, R. (1999). Knowledge transfer in international acquisitions. Journal of International Business Studies, 41(1), 5-20.

[5] Cohen, W. M., \& Levinthal, D. A. (1989). Innovation and learning: the two faces of R \& D. The economic journal, 99(397), 569-596.

[6] Connelly, C. E., \& Kevin Kelloway, E. (2003). Predictors of employees' perceptions of knowledge sharing cultures Leadership \& Organization Development Journal, 24(5), 294-30.

[7] Cummings, J. L., \& Teng, B. S. (2003). Transferring R\&D knowledge: the key factors affecting knowledge transfer success. Journal of Engineering and technology management, 20(1-2), 39-68.

[8] Davenport, T. H., \& Prusak, L. (1998). Working

knowledge: How organizations manage what they know. Harvard Business Press.

[9] Dedrick, J., Carmel, E., \& Kraemer, K. L. (2011). A dynamic model of offshore software development. Journal of Information Technology, 26(1), 1-15.

[10] Dixon, N. M. (2017). The organizational learning cycle: How we can learn collectively. Routledge.

[11] Gao, J., \& Bernard, A. (2017). An overview of knowledge sharing in new product development. The International Journal of Advanced Manufacturing Technology, 1-6.

[12] Garrison, G., Wakefield, R. L., Xu, X., \& Kim, S. H. (2010). Globally distributed teams: The effect of diversity on trust, cohesion and individual performance. ACM SIGMIS Database: the DATABASE for Advances in Information Systems, 41(3), 27-48.

[13] Gibson, C. B., \& Gibbs, J. L. (2006). Unpacking the concept of virtuality: The effects of geographic dispersion, electronic dependence, dynamic structure, and national diversity on team innovation. Administrative Science Quarterly, 51(3), 451-495.

[14] Goffin, K., \& Koners, U. (2011). Tacit knowledge, lessons learned, and new product development. Journal of Product Innovation Management, 28(2), 300-318.

[15] Goh, S. C. (2002). Managing effective knowledge transfer: an integrative framework and some practice. implications. Journal of knowledge management, 6(1), 23-30. [16] Griffith, T. L., Sawyer, J. E., \& Neale, M. A. (2003). Virtualness and knowledge in teams: Managing the love triangle of organizations, individuals, and information technology. MIS Quarterly, 265-287.

[17] Hackney, R., Desouza, K., \& Loebbecke, C. (2005). Cooperation or competition: knowledge sharing processes in 
inter-organizational networks. In Knowledge Management: Nurturing Culture, Innovation, and Technology (pp. 79-91). [18] Han, B. M., \& Anantatmula, V. S. (2007). Knowledge sharing in large IT organizations: a case study. Vine, 37(4), 421-439.

[19] Hendriks, P. (1999). Why share knowledge? The influence of ICT on the motivation for knowledge sharing. Knowledge and process management, 6(2), 91.

[20] Jennex, E. -M., Smolnik, S., Croasdell, D. (2014). Knowledge Management Success in Practice. 47th Hawaii International Conference on System Science. IEEE Computer Society, pp. 3615-3624. DOI 10.1109/HICSS.2014.450 [21] Joshi, K. D., Sarker, S., \& Sarker, S. (2007). Knowledge transfer within information systems development teams: Examining the role of knowledge source attributes. Decision Support Systems, 43(2), 322-335.

[22] Kanat, S., Atilgan, T. (2014). Effects of Knowledge Management on Supply Chain Management in the Clothing Sector: Turkish Case. FIBRES \& TEXTILES inEastern Europe, 1(103): 9-13

[23] Karlsen, J. T., \& Gottschalk, P. (2004). Factors affecting knowledge transfer in IT projects. Engineering Management Journal, 16(1), 3-11.

[24] Kogut, B., \& Zander, U. (2003). Knowledge of the firm and the evolutionary theory of the multinational corporation. Journal of international business studies, 34(6), 516-529.

[25] Malhotra, A., Majchrzak, A., \& Rosen, B. (2007). Leading virtual teams. The Academy of Management Perspectives, 21(1), 60-70.

[26] Montoya, M. M., Massey, A. P., Hung, Y. T. C., \& Crisp, C. B. (2009). Can you hear me now? Communication in virtual product development teams. Journal of Product Innovation Management, 26(2), 139-155.

[27] Moreland, R. L., Argote, L., \& Krishnan, R. (1996). Socially shared cognition at work: Transactive memory and group performance. [28] Nonaka, I. (2008). The KnowledgeCreating Company Harvard Business Review Classics.

[29] Oshri, I., Van Fenema, P., \& Kotlarsky, J. (2008).

Knowledge transfer in globally distributed teams: the role of transactive memory. Information Systems Journal, 18(6), 593-616.

[30]Riege, A. (2005). Three-dozen knowledge-sharing barriers managers must consider. Journal of knowledge management, 9(3), 18-35.

[31] Ritchie, J., \& Lewis, J. (Eds.). (2013). Qualitative research practice: A guide for social science students and researchers. Sage.

[32] Robey, D., Khoo, H. M., \& Powers, C. (2000). Situated learning in cross-functional virtual teams. Technical Communication, 47(1), 51-66.

[33] Sambamurthy, V., \& Subramani, M. (2005). Special issue on information technologies and knowledge management. MIS Quarterly, 1-7.

[34] Starbuck W. H.(1992).Learning by knowledge-intensive firms. Journal of Management Studies, 29(6), 713-740.

[35] Subramaniam, M. \& Venkatraman, N. (2001). Determinants of transnational new product development capability: Testing the influence of transferring and deploying tacit overseas knowledge. Strategic management journal, 22(4), 359-378.

[36] Szulanski, G. (2000). The process of knowledge transfer: A diachronic analysis of stickiness. Organizational behavior and human decision processes, 82(1), 9-27. [37] Tanriverdi, H. (2005). Information technology relatedness, knowledge management capability, and performance of multibusiness firms. MIS Quarterly, 311-334. [38] Vance, D., \& Eynon, J. (1998). On the requirements of knowledge transfer using information systems: A schema whereby such transfer is enhanced. AMCIS 1998 Proceedings, 212.

[39] Walsham, G. (1995). Interpretive case studies in IS research: nature and method. European Journal of information systems, 4(2), 74-81.

[40] Walsham, G. (2006). Doing interpretive research. European journal of information systems, 15(3), 320-330. [41] Zander, U., \& Kogut, B. (1995). Knowledge and the speed of the transfer and imitation of organizational capabilities: An empirical test. Organization Science, 6(1), 76-92 